\title{
СОВРЕМЕННОЕ СОСТОЯНИЕ ДИАГНОСТИКИ И ЛЕЧЕНИЯ РЕВМАТОИДНОГО АРТРИТА
}

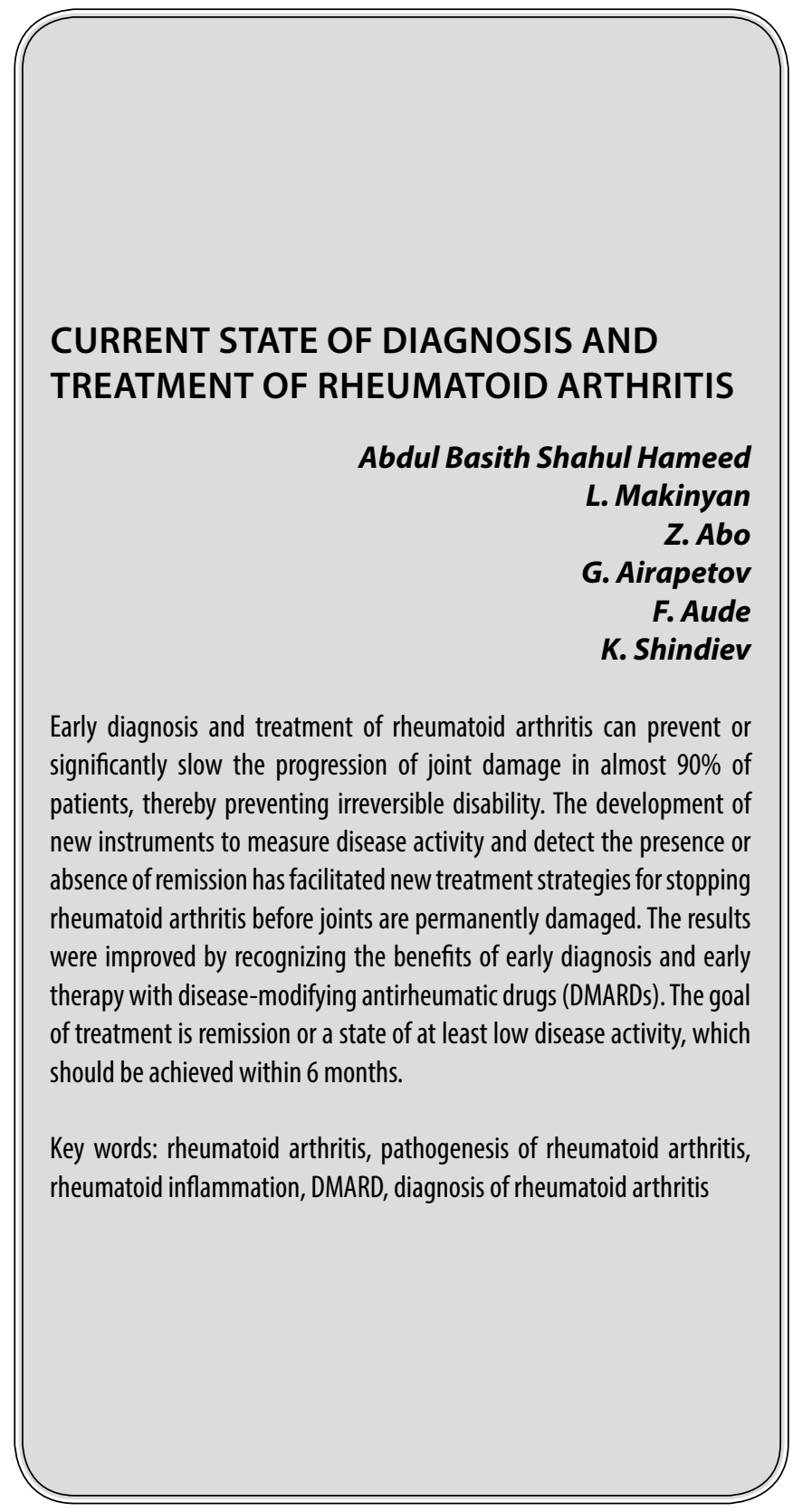

\section{Введение}

$\mathbf{P}$ евматоидный артрит (РА) - это хроническое воспалительное заболевание суставов, распространенность которого во всем мире составляет около 5 на 1000 взрослых. Заболевание поражает женщин в 2-3 раза чаще, чем мужчин, и возникает в любом возрасте. Пик заболеваемости приходится на шестое десятилетие
Шахул Хамид Абдул Баситх

К.м.Н., Российский университет дружбы народов,

Москва

drabdulbasi@gmail.com

Макинян Левон Гагикович

К.м.н., дочент, Российский университет дружбы народов, Москва

dr.makinyan@gmail.com

Абу заалан Вессам

К.м.н., Российский университет дружбы народов,

Москва

wsameeexx@gmail.com

Айрапетов Георгий Александрович

К.м.н., дочент, Ставропольский государственный медицинский университет

airapetovga@yandex.ru

Ауде Фади Салимович

К.м.н., врач травматолог-ортопед в ГКБ № 31,

Москва

Dr.awde.fs@gmail.com

Шиндиев Курбан Ахмедович

К.м.н., Российский университет дружбы народов,

Москва

Kurban-Shindiev@mail.ru

Аннотация. Ранняя диагностика и лечение РА могут предотвратить или существенно замедлить прогрессирование поражения суставов у почти 90\% пациентов, тем самым предотвращая необратимую инвалидность. Разработка новых инструментов для измерения активности заболевания и выявления наличия или отсутствия ремиссии облегчила новые стратегии лечения для остановки РА до того, как суставы будут необратимо повреждены. Результаты были улучшены за счет признания преимуществ ранней диагностики и ранней терапии модифицирующими болезнь противоревматическими препаратами (DMARD). Целью лечения является ремиссия или состояние хотя бы низкой активности заболевания, которое должно быть достигнуто в течение 6 месяцев.

Ключевые слова: ревматоидный артрит, патогенез ревматоидного артрита, ревматоидное воспаление, DMARD, диагностика ревматоидного артрита.

[1]. Ранее РА приводил к инвалидности, нетрудоспособности и повышенной смертности. Недавнее улучшение результатов было достигнуто за счет лучшего понимания патофизиологии РА и разработки более эффективных методов измерения результатов и методов лечения.

Патофизиология РА включает хроническое воспаление синовиальной оболочки, которое может разрушить 
суставной хрящ и околосуставную кость [2]. Недавние открытия, касающиеся биологических путей, улучшили понимание явлений, связанных с ревматоидным воспалением и их последствий. Были идентифицированы новые молекулы и клетки в биологическом пути, которые являются мишенями для терапевтического вмешательства.

В этом обзоре обобщены текущие данные о патофизиологии, диагностике и лечении РА.

\section{Патофизиология \\ ревматои ного артрита}

РА характеризуется инфильтрацией синовиальной мембраны во множестве суставов Т-клетками, В-клетками и моноцитами. Этому процессу предшествует активация эндотелиальных клеток; неоваскуляризация (рост новых кровеносных сосудов) - еще одна отличительная черта синовита при РА. Расширение синовиальных фибробластоподобных и макрофагоподобных клеток приводит к гиперпластическому слою синовиальной выстилки. Эта расширенная синовиальная мембрана, часто называемая «паннусом», проникает в околосуставную кость в месте соединения хрящ-кость и приводит к эрозии костей и деградации хряща. Молекулы, такие как активатор рецептора лиганда ядерного фактора кВ (RANKL), простагландины и матриксные металлопротеиназы, индуцируются провоспалительными цитокинами, включая фактор некроза опухоли (TNF) и интерлейкин (IL) -6 , и опосредуют признаки и симптомы заболевания, включая боль и отек, а также разрушение хрящей и костей. 6 Стимуляция RANKL, TNF и IL-6 генерирует остеокласты внутри синовиальной мембраны и способствует повреждению костей [3]. Эти молекулярные и клеточные события приводят к клиническому проявлению болезни. Прогрессирование поражения суставов неразрывно связано с отеком суставов [4].

Причина РА неизвестна. Однако генетические факторы и факторы окружающей среды способствуют развитию РА. Многие локусы генов связаны с RA (Box) [5]. Однако некоторые антигены HLA класса II, такие как HLA-DRB1 * 01 и HLA-DRB1 * 04, содержат «общий» эпитоп - участок из 5 аминокислот в области ответственны за презентацию антигена Т-лимфоцитам - и наиболее тесно связаны c RA [6]. Гены с более слабыми ассоциациями (вставка) также могут вносить свой вклад, особенно за счет взаимодействия ген-ген и ген-окружающая среда [7]. Факторами риска развития RA из окружающей среды являются курение, периодонтит, и характеристики микробиома кишечника, рта и легких, а также вирусные инфекции [8, 9]. Что касается микробиома, то виды Prevotella, которые распространяются в желудочно-кишечном тракте при раннем PA, и Porphyromonas gingivalis, связанные с па- родонтитом, могут играть роль в патогенезе [10]. Новые данные предполагают, что бактерии могут перемещаться из кишечника в ткани, вызывая воспаление и аутоиммунитет [11]. Связь между генетикой и окружающей средой очевидна на основании недавних наблюдений, что молекулы HLA-DR пациентов с RA представляют пептиды аутоантигенов, имеющие гомологию последовательностей с эпитопами белков комменсальных видов бактерий, присутствующих в RA [12]. Сходство между аминокислотными последовательностями аутоантигенов и были описаны бактериальные или вирусные белки [13]. Также замешана инфекция вируса Эпштейна-Барра, что дополнительно подтверждается недавними наблюдениями о том, что ядерный антиген 2 транскрипционного фактора EB (EBNA2) связывается преимущественно с генетическими локусами, связанными с RA и другими аутоиммунными заболеваниями [14].

Эпигенетические модификации, такие как метилирование ДНК и ацетилирование гистонов, также способствуют воспалительным реакциям. Посттрансляционные модификации белков, такие как цитруллинирование аргинина пептидиларгининдезиминазой или карбамилирование лизина, способствуют нарушению иммунологической толерантности за счет создания неоэпитопов различных аутологичных белков (например, коллагена, виментина, фибриногена) [15], что приводит к образованию аутоантител против аутоантигенов (например, антицитруллинированного пептида). антитела [ACPA]), антитела к IgG (ревматоидный фактор [RF]), ядерные антигены или аутоантигены, которые перекрестно реагируют с бактериальными или вирусными антигенами, такими как Prevotella или вирус Эпштейна-Барра. Эти аутоантитела могут образовывать иммунные комплексы, которые могут активировать комплемент, дополнительно увеличивая воспалительные реакции. RF и ACPA вместе могут способствовать существенному воспалительному ответу, тогда как только АСРА вызывают небольшое воспаление. RF увеличивают иммунные комплексы, образованные АСРА, и усиливают воспалительный ответ, вызываемый иммунными комплексами и активацией комплемента $[8,16,17]$.

Аутоантитела развиваются до появления признаков и симптомов [18]. Эта стадия называется «пре-РА» и может длиться от менее 1 до более 10 лет. Время до появления симптомов РА связано с профилем аутоантител. У людей, которые экспрессируют только АСРА, симптомы развиваются через 5-10 лет после появления аутоантител, тогда как у людей, у которых развиваются ACPA и RF, а также повышенный уровень C-реактивного белка (CRP), появляются симптомы. через несколько месяцев после появления третьего из этих факторов [18]. У некоторых пациентов с пре-РА были отмечены незначительные воспалительные изменения в синовиальной оболочке. Даже при установ- 
ленном РА явные воспалительные изменения, выявленные гистологически, не всегда сопровождаются клиническими признаками и симптомами [19]. Ранние проявления РА варьируются от легкого артрита с небольшим количеством пораженных суставов до тяжелого полиартикулярного заболевания и от состояния отрицательных аутоантител до множественных положительных аутоантител. На очень ранней стадии заболевания структурные повреждения еще не наблюдаются, тогда как на более поздних стадиях наблюдается эрозионное заболевание или сужение суставной щели как индикатор деградации хряща. При отсутствии адекватного лечения РА прогрессирует в более однородное деструктивное заболевание.

\section{Клиническая картина}

РА - это полиартикулярно-симметричное заболевание, которое поражает несколько суставов с обеих сторон. Пациент с РА обычно жалуется на боль и отек в суставах рук и ног. Припухлость в основном наблюдается в запястьях и пястно-фаланговых, плюснефаланговых и проксимальных межфаланговых суставах. Это сопровождается утренней скованностью суставов, продолжающейся более 30 минут, а обычно до нескольких часов. При синовите и выпоте опухоль обычно «мягкая», в отличие от «твердой» (костной) опухоли при остеоартрите. Когда поражены пальцы, опухоль сосредотачивается вокруг сустава (веретенообразная), а не охватывает весь палец («колбасный палец»), как это наблюдается при псориатическом артрите. Могут быть поражены как мелкие, так и крупные суставы, хотя дистальные межфаланговые суставы поражаются редко. К малым суставам относятся пястно-фаланговые, плюснево-фаланговые, проксимальные межфаланговые суставы и суставы запястья. К крупным суставам относятся голеностопные, коленные, локтевые и плечевые суставы.

При недостаточном лечении РА могут развиться внесуставные проявления. Наиболее частыми являются ревматоидные узелки (твердые подкожные уплотнения возле костных выступов, таких как локоть). Более серьезным проявлением является ревматоидный васкулит, некротическое воспаление артерий малого или среднего размера, в основном затрагивающее кожу, vasa nervorum, а иногда и артерии других органов.

Пациенты с РА могут иметь несколько сопутствующих заболеваний. Сердечно-сосудистые заболевания - частое последствие хронического воспаления и основная причина смерти у людей с РА. У пациентов с РА сердечно-сосудистые заболевания более тесно связаны с активностью заболевания, чем с традиционными сердечно-сосудистыми факторами риска [20]. Лечение таргетными биологическими агентами снижает сердечно-сосудистый риск [21]. Интерстициальное заболева- ние легких может быть проявлением РА или может быть осложнением лечения РА, такие как метотрексат и лефлуномид [22].

РА влияет на физическое функционирование, производительность труда и качество жизни. При недостаточном лечении 80\% пациентов будут иметь смещенные суставы, а 40\% не смогут работать в течение 10 лет от начала заболевания. Качество жизни, по оценке краткого обзора состояния здоровья из 36 пунктов, подобен или хуже, чем тот, который связан с сердечно-сосудистыми заболеваниями и диабетом [23]. РА влияет на все виды повседневной жизни [24]. необратима при РА, приводит к инвалидности; пациенты с необратимым повреждением суставов никогда не восстановят нормальную физическую функцию, даже если впоследствии будет достигнута клиническая ремиссия (т.е. отсутствие признаков воспаления, таких как отек суставов и повышенный уровень СРБ). Даже самые эффективные методы лечения не устранят повреждение суставов [25]. Развитие рентгенологических результатов варьируется от суставов с минимальными аномалиями до серьезных деструктивных изменений, проявляющихся в виде эрозий костей и сужения суставной щели, отражающих изменения хряща (поскольку хрящ радиопрозрачен, изменения можно только увидеть косвенно). Повреждение хряща в большей степени способствует необратимой инвалидности, чем повреждение костей.

\section{Аиагностика и лечение}

На ранних стадиях заболевания РА может поражать только 1 или несколько суставов. Одновременно или даже раньше развивается воспаление сухожилий (теносиновит). Наличие тендосиновита, например, сухожилия локтевого сгибателя запястья, и субклиническое синовиальное воспаление можно обнаружить с помощью визуализации с помощью цветной допплерографии или магнитно-резонансной томографии с усилением гадолиния, которые демонстрируют расширение внутрисуставных мягких тканей или гиперваскуляризацию синовиальной оболочки.

Диагностических критериев для РА не существует. Однако критерии классификации 2010 г., хотя в первую очередь разработаны для выявления однородных популяций пациентов в клинических исследованиях РА, могут помочь врачам установить диагноз $[26,27]$; различия между классификацией и диагнозом были резюмированы в недавнем отчете [28]. Для классификации РА требуется наличие как минимум 1 клинически опухшего сустава и как минимум 6 из 10 баллов по системе баллов. Вовлечение суставов на основе физикального обследования. или визуализация с помощью ультразвука или магнитно-резонансной томографии дает до 5 баллов; повышенный уровень RF, ACPA или обоих 
дает 2 дополнительных балла (или 3 балла с уровнями> 3-кратного верхнего предела нормы); и повышенная реакция острой фазы реагентов (APR), такая как повышенный уровень CRP или скорость оседания эритроцитов, и продолжительность симптомов (6 недель) дают 1 дополнительный балл каждый. Эти критерии 2010 г. имеют чувствительность $82 \%$ и специфичность $61 \%$. Чувствительность новых критериев классификации была на $11 \%$ выше, а специфичность на 4\% ниже по сравнению с критериями 1987 года [27].

Поскольку ранняя диагностика и лечение предотвращают прогрессирование поражения суставов у $90 \%$ пациентов с ранним РА [29], важно как можно скорее выявлять пациентов с РА. Специфические симптомы, которые могут указывать на возможный РА, включают суставную боль и отек пястно-фаланговых суставов, плюснефаланговых суставов или обоих, утреннюю скованность суставов пальцев в течение 30 минут или дольше и положительность аутоантител [30].

Первоначальная оценка требует обследования суставов, а также серологического тестирования на наличие аутоантител и APR. Для последующего наблюдения важны совместная оценка, оценка APR и оценка результатов, сообщаемых пациентом, таких как общая оценка пациентом активности заболевания и оценка физических функций. Комбинированные измерения, которые включают подсчет суставов, т. Е. Количество болезненных и опухших суставов, представляют собой лучший способ оценки активности заболевания РА на практике (и в испытаниях), поскольку они отражают наиболее важные аспекты заболевания в единой шкале. Эти оценки, а именно индекс клинической активности заболевания (CDAI), оценка активности заболевания с использованием 28 подсчетов суставов (DAS28) или упрощенный индекс активности заболевания (SDAl), коррелируют с такими исходами, как прогрессирование повреждения и функциональные нарушения [31, 32]. меры позволяют количественно оценить активность заболевания, а состояния активности заболевания, основанные на конкретных пороговых значениях этих индексов, были определены, чтобы помочь направить лечение. Цели лечения включают ремиссию, определяемую как отсутствие активности заболевания, и низкую активность заболевания, соответствующую умеренной остаточной активности с низким риском прогрессирования повреждения. Таким образом, эти 2 состояния контрастируют с состояниями средней и высокой активности заболевания, которые указывают на неконтролируемое заболевание, связанное с прогрессированием во времени. Среди всех доступных индексов, CDAI является наиболее простым для выполнения. Это простое числовое суммирование 4 переменных: опухшие и болезненные суставы (с использованием 28 подсчетов суставов), общая оценка пациента и глобальная оценка оценщика, обе по 10-сантиметровой визуальной аналоговой шкале. CDAI варьируется от 0 до 76 (более высокие баллы - хуже). Формула CDAI и другие индексы, включая соответствующие пороговые значения, определяющие состояния активности заболевания.

Инструменты оценки, в первую очередь CDAI, должны использоваться для наблюдения за терапией с использованием подхода «лечение до цели» 45. Эта стратегия состоит из лечения и адаптации терапии по мере необходимости, чтобы получить улучшение индекса активности заболевания как минимум на 50.\% в течение 3 месяцев и, таким образом, вероятность достижения низкой активности заболевания или ремиссии через 6 месяцев составляет более 50\%. Терапевтическая цель - достичь клинической ремиссии (особенно при раннем РА) или низкой активности заболевания (при установленном РА, если ремиссия недостижима) 46 Клиническая ремиссия, на которую указывают CDAI или SDAI,- это состояние, при котором физическая функция максимально улучшается и прогрессирует поражения суставов прекращено. Американский колледж ревматологии (ACR) и Европейская лига против ревматизма (EULAR) недавно определили критерии ремиссии, основанные на булевом подходе или на индексах, а именно SDAI и CDAI [33]. для достижения клинической ремиссии в соответствии с определением по этим показателям, а не в соответствии с уменьшением субклинического воспаления, измеренным, например, с помощью ультразвука. Нет никаких доказательств того, что лечение, выходящее за рамки клинической ремиссии, как это определено индексами ACR и EULAR или булевыми критериями, улучшает исходы; следовательно, к нему не следует стремиться.

Хотя РА неизлечима, современные терапевтические подходы позволяют добиться превосходного контроля над заболеванием. Пациентов с РА необходимо лечить противоревматическими препаратами, модифицирующими заболевание (DMARD). DMARD определяется как лекарство, которое препятствует появлению признаков и симптомов РА, улучшает физическую функцию и препятствует прогрессированию поражения суставов. Методы лечения, которые только улучшают симптомы, например нестероидные противовоспалительные препараты или обезболивающие, не предотвращают прогрессирование повреждений и необратимую инвалидность. Эти препараты не являются БПВП и должны использоваться только в качестве дополнительной симптоматической терапии или в течение короткой фазы до установления диагноза.

\section{Зак^ючение}

Недавно полученные знания о патогенезе, оптимальном лечении и оптимальных показателях исходов РА значительно улучшили терапию РА. Ранняя диагностика 
РА позволяет клиницистам незамедлительно назначать метотрексат в качестве начального БПВП, купируя заболевание у значительной части пациентов. Критерии классификации 2010 г. облегчают раннее выявление пациентов с РА для клинических исследований и могут помочь в постановке клинического диагноза. Эффекты терапии следует тщательно контролировать с помощью показателей активности заболевания, таких как CDAI. Отсутствие ремиссии или низкая активность заболева- ния требует изменения терапии в соответствии с рекомендациями по назначению лечения. Если метотрексат (в сочетании с краткосрочными глюкокортикоидами) не вызывает ремиссии, следует добавить биологические БПВП или ингибиторы JAK, особенно у пациентов с сохраняющейся высокой активностью заболевания, наличием аутоантител или ранее существовавшим повреждением. С помощью этих методов можно предотвратить неблагоприятные последствия РА.

\section{ЛИТЕРАТУРА}

1. Myasoedova E., Crowson C.S., Kremers H.M., Therneau T.M., Gabriel S.E. Is the incidence of rheumatoid arthritis rising? results from Olmsted County, Minnesota, 1955-2007. Arthritis Rheum. 2010;62(6):1576-1582.

2. Aletaha D., Funovits J., Smolen J.S. Physical disability in rheumatoid arthritis is associated with cartilage damage rather than bone destruction. Ann Rheum Dis. 2011;70(5):733-739.

3. Redlich K., Smolen J.S. Inflammatory bone loss: pathogenesis and therapeutic intervention. Nat Rev Drug Discov. 2012;11(3):234-250.

4. Aletaha D., Smolen J.S. Joint damage in rheumatoid arthritis progresses in remission according to the Disease Activity Score in 28 joints and is driven by residual swollen joints. Arthritis Rheum. 2011;63(12):3702-3711.

5. Viatte S., Barton A. Genetics of rheumatoid arthritis susceptibility, severity, and treatment response. Semin Immunopathol. 2017;39(4):395-408.

6. Gregersen P.K., Silver J., Winchester R.J. The shared epitope hypothesis: an approach to understanding the molecular genetics of susceptibility to rheumatoid arthritis. Arthritis Rheum. 1987;30(11):1205-1213.

7. Raychaudhuri S. Recent advances in the genetics of rheumatoid arthritis. Curr Opin Rheumatol. 2010;22(2):109-118.

8. Tan E.M., Smolen J.S. Historical observations contributing insights on etiopathogenesis of rheumatoid arthritis and role of rheumatoid factor. J Exp Med. 2016;213(10):1937-1950.

9. Scher J.U., Sczesnak A., Longman R.S., et al. Expansion of intestinal Prevotella copri correlates with enhanced susceptibility to arthritis. Elife. $2013 ; 2: \mathrm{e} 01202$.

10. Wegner N., Wait R., Sroka A., et al. Peptidylarginine deiminase from Porphyromonas gingivalis citrullinates human fibrinogen and a-enolase: implications for autoimmunity in rheumatoid arthritis. Arthritis Rheum. 2010;62(9): 2662-2672.

11. Manfredo Vieira S., Hiltensperger M., Kumar V., et al. Translocation of a gut pathobiont drives autoimmunity in mice and humans. Science. 2018; 359(6380):11561161.

12. Pianta A., Arvikar S.L., Strle K., et al. Two rheumatoid arthritis-specific autoantigens correlate microbial immunity with autoimmune responses in joints.J Clin Invest. 2017; 127(8):2946-2956.

13. Alam J., Kim Y.C., Choi Y. Potential role of bacterial infection in autoimmune diseases: a new aspect of molecular mimicry. Immune Netw. 2014;14(1):7-13.

14. Harley J.B., Chen X., Pujato M., et al. Transcription factors operate across disease loci, with EBNA2 implicated in autoimmunity. Nat Genet. $2018 ; 50(5): 699-707$.

15. Ospelt C., Gay S., Klein K. Epigenetics in the pathogenesis of RA. Semin Immunopathol. 2017;39 (4):409-419.

16. Aletaha D., Alasti F., Smolen J.S. Rheumatoid factor, not antibodies against citrullinated proteins, is associated with baseline disease activity in rheumatoid arthritis clinical trials. Arthritis Res Ther. 2015;17:229.

17. Sokolove J., Johnson D.S., Lahey L.J., et al. Rheumatoid factor as a potentiator of anti-citrullinated protein antibody-mediated inflammation in rheumatoid arthritis. Arthritis Rheumatol. 2014;66(4):813-821.

18. Nielen M.M., van Schaardenburg D., Reesink H.W., et al. Specific autoantibodies precede the symptoms of rheumatoid arthritis: a study of serial measurements in blood donors. Arthritis Rheum. 2004;50(2):380-386.

19. de Hair M.J., van de Sande M.G., Ramwadhdoebe T.H., et al. Features of the synovium of individuals at risk of developing rheumatoid arthritis: implications for understanding preclinical rheumatoid arthritis. Arthritis Rheumatol. 2014;66(3):513-522.

20. Crowson C.S., Rollefstad S., Ikdahl E., et al; A Trans-Atlantic Cardiovascular Consortium for Rheumatoid Arthritis (ATACC-RA). Impact of risk factors associated with cardiovascular outcomes in patients with rheumatoid arthritis. Ann Rheum Dis. 2018;77(1):48-54.

21. Low A.S., Symmons D.P., Lunt M., et al; British Society for Rheumatology Biologics Register for Rheumatoid Arthritis (BSRBR-RA) and the BSRBR Control Centre Consortium. Relationship between exposure to tumour necrosis factor inhibitor therapy and incidence and severity of myocardial infarction in patients with rheumatoid arthritis. Ann Rheum Dis. 2017;76(4):654-660.

22. Bongartz T., Nannini C., Medina-Velasquez Y.F., et al. Incidence and mortality of interstitial lung disease in rheumatoid arthritis: a population-based study. Arthritis Rheum. 2010;62(6):1583-1591.

23. Matcham F., Scott I.C., Rayner L., et al. The impact of rheumatoid arthritis on quality-of-life assessed using the SF-36: a systematic review and meta-analysis. Semin Arthritis Rheum. 2014;44(2): 123-130.

24. Radner H., Smolen J.S., Aletaha D. Comorbidity affects all domains of physical function and quality of life in patients with rheumatoid arthritis. Rheumatology (0xford). 2011;50(2):381-388. 
25. Aletaha D., Strand V., Smolen J.S., Ward M.M. Treatment-related improvement in physical function varies with duration of rheumatoid arthritis: a pooled analysis of clinical trial results. Ann Rheum Dis. 2008;67(2):238-243.

26. Aletaha D., Neogi T., Silman A., et al. 2010 rheumatoid arthritis classification criteria: an American College of Rheumatology/European League Against Rheumatism collaborative initiative. Ann Rheum Dis. 2010;69:1580-1588.

27. Radner H., Neogi T., Smolen J.S., Aletaha D. Performance of the 2010 ACR/EULAR classification criteria for rheumatoid arthritis: a systematic literature review. Ann Rheum Dis. 2014;73(1):114-123

28. Aggarwal R., Ringold S., Khanna D., et al. Distinctions between diagnostic and classification criteria? Arthritis Care Res (Hoboken). 2015;67(7): 891-897

29. Goekoop-Ruiterman Y.P., de Vries-Bouwstra J.K., Allaart C.F., et al. Clinical and radiographic outcomes of four different treatment strategies in patients with early rheumatoid arthritis (the BeSt study): a randomized, controlled trial. Arthritis Rheum. 2005;52(11):3381-3390

30. Emery P., Breedveld F.C., Dougados M., Kalden J.R., Schiff M.H., Smolen J.S. Early referral recommendation for newly diagnosed rheumatoid arthritis: evidence based development of a clinical guide. Ann Rheum Dis. 2002;61(4):290-297.

31. Aletaha D., Nell V.P.K., Stamm T., et al. Acute phase reactants add little to composite disease activity indices for rheumatoid arthritis: validation of a clinical activity score. Arthritis Res Ther. 2005;7 (4): R796-R806.

32. Smolen J.S., Breedveld F.C., Burmester G.R., et al. Treating rheumatoid arthritis to target: 2014 update of the recommendations of an international task force. Ann Rheum Dis. 2016;75(1):3-15.

33. Aletaha D., Alasti F., Smolen J.S. Optimisation of a treat-to-target approach in rheumatoid arthritis: strategies for the 3-month time point. Ann Rheum Dis. 2016;75(8):1479-1485.

34. Felson D.T., Smolen J.S., Wells G., et al. American College of Rheumatology/European League Against Rheumatism provisional definition of remission in rheumatoid arthritis for clinical trials. Ann Rheum Dis. 2011;70(3):404-413.

\footnotetext{
๑ Шахул Хамид Абдул Баситх ( drabdulbasi@gmail.com ), Макинян Левон Гагикович (dr.makinyan@gmail.com ),

Абу Заалан Вессам ( wsameeexx@gmail.com ), Айрапетов Георгий Александрович (airapetovga@yandex.ru ),

Ауде Фади Салимович ( Dr.awde.fs@gmail.com ), Шиндиев Курбан Ахмедович (Kurban-Shindiev@mail.ru).
}

Журнал «Современная наука: актуальные проблемы теории и практики»

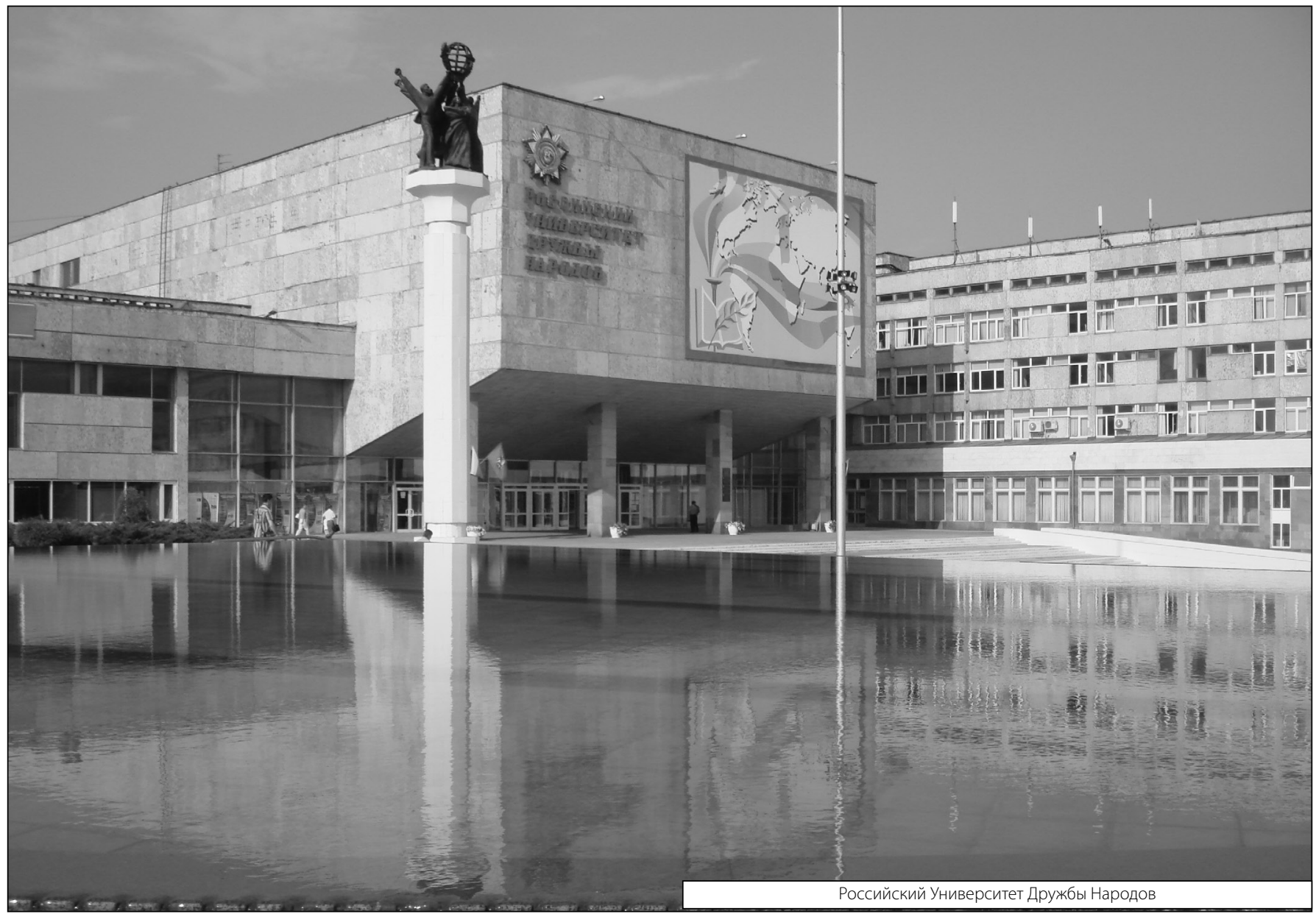

